\title{
Mechanisms of Odor Coding in Coniferous Bark Beetles: From Neuron to Behavior and Application
}

\author{
Martin N. Andersson \\ Department of Biology, Lund University, 22362 Lund, Sweden \\ Correspondence should be addressed to Martin N. Andersson, martin_n.andersson@biol.lu.se
}

Received 3 October 2011; Accepted 12 December 2011

Academic Editor: John A. Byers

Copyright (๑) 2012 Martin N. Andersson. This is an open access article distributed under the Creative Commons Attribution License, which permits unrestricted use, distribution, and reproduction in any medium, provided the original work is properly cited.

Coniferous bark beetles (Coleoptera: Curculionidae: Scolytinae) locate their hosts by means of olfactory signals, such as pheromone, host, and nonhost compounds. Behavioral responses to these volatiles are well documented. However, apart from the olfactory receptor neurons (ORNs) detecting pheromones, information on the peripheral olfactory physiology has for a long time been limited. Recently, however, comprehensive studies on the ORNs of the spruce bark beetle, Ips typographus, were conducted. Several new classes of ORNs were described and odor encoding mechanisms were investigated. In particular, links between behavioral responses and ORN responses were established, allowing for a more profound understanding of bark beetle olfaction. This paper reviews the physiology of bark beetle ORNs. Special focus is on I. typographus, for which the available physiological data can be put into a behavioral context. In addition, some recent field studies and possible applications, related to the physiological studies, are summarized and discussed.

\section{Introduction}

Bark beetles (Coleoptera: Curculionidae: Scolytinae) constitute some of the most destructive pests of coniferous trees throughout the world, destroying forests of great economic value. Currently, the large-scale outbreak of the mountain pine beetle, Dendroctonus ponderosae, in North America has resulted in the loss of hundreds of millions $\mathrm{m}^{3}$ timber and turned the forests into major sources of carbon release [1]. In Europe and parts of Asia [2, 3], the European spruce bark beetle, Ips typographus (Figure 1), is considered the most destructive bark beetle of coniferous forests $[4,5]$.

Bark beetles, like most insects, locate their hosts mainly by means of olfactory signals. It is clear that they utilize both attractants and antiattractants that emanate from host and nonhost plants, as well as from conspecific and heterospecific bark beetle individuals [3, 6-10]. The odor molecules are transported downwind from their source of release as an odor plume with a complex structure [11-13]. Molecules are picked up by olfactory receptors (ORs) or ionotropic receptors (IRs) [14], located mainly in the antennae and maxillary palps. Specifically, the ORs are present in the cell membrane of olfactory receptor neuron (ORN) dendrites that, in turn, are housed within olfactory sensilla [15]. The ORs are encoded by a large and diverse family of olfactory receptor genes [16]. Each ORN is generally thought to express only one member from this family in addition to the widely expressed coreceptor, Orco [17]. IRs act in combinations of up to three subunits that are comprised of odor-specific receptors and one or two broadly expressed coreceptors [14]. These receptors are expressed in neurons that do not express ORs. When an odor molecule binds to a receptor, the ORN sends a neuronal signal to the primary olfactory center of the brain, the antennal lobe. Typically, the signal that is generated by an ORN is an increase in the firing frequency of action potentials (excitation), but some odorants may instead cause a decrease in firing activity (inhibition). ORNs can be divided into classes based on their odor response profiles. Often, ORNs are fairly specific and activated by only one or a few compounds, but some appear to have a broader tuning. In addition, each compound often activates more than one type of ORN, and thus, the odor input is thought to be constructed as a combinatorial code [18]. 


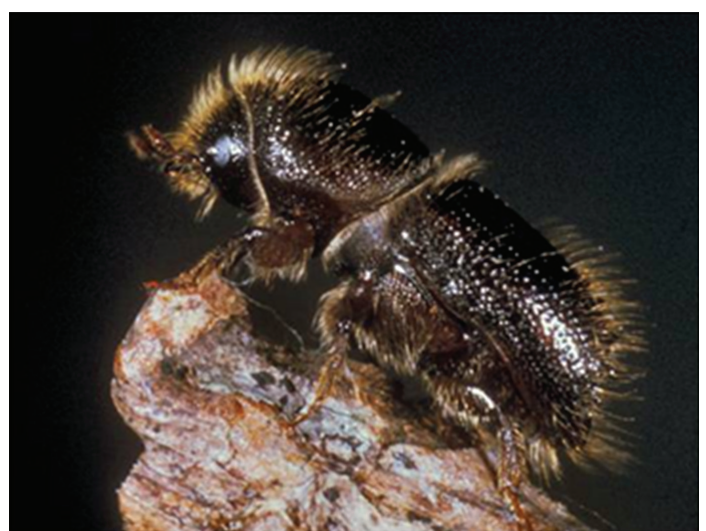

Figure 1: The European spruce bark beetle, Ips typographus. Photo: Göran Birgersson.

In contrast to the well-studied chemical ecology of bark beetles, until recently, little was known about the physiological responses of individual bark beetle ORNs. Mainly in the 1980s, Single-sensillum recordings (SSR) were carried out, primarily identifying classes of ORNs that responded to various pheromone compounds. Some decades later, comprehensive studies on I. typographus have characterized additional ORNs that respond also to host and nonhost plant compounds [19] and have provided novel insights into potential odor coding mechanisms in insects in general [8]. This review summarizes the results from early and recent studies on the physiology of ORNs in conifer-feeding bark beetles. Particular focus is on I. typographus, for which a sufficient amount of information has emerged in order to bridge the physiological data with previously recorded behavioral responses to several semiochemicals. In addition, some recent behavioral studies with connections to olfactory physiology are summarized and possible applications discussed. First, however, a brief overview of the semiochemicals that are used by I. typographus in host selection is presented.

\section{Host Selection by I. typographus}

The male is the initial host seeking, or "pioneering," sex of $I$. typographus. Once a male has located a suitable host material to colonize, it releases an aggregation pheromone, a mixture of (4S)-cis-verbenol and 2-methyl-3-buten-2-ol [20], which attracts individuals of both sexes. Although the olfactorymediated host location behavior of I. typographus has been extensively studied, it is not known how the pioneering males locate a suitable host tree, as no primary attraction (in the absence of pheromone) to spruce volatiles has been demonstrated. However, spruce volatiles may modulate the pheromone response [9] or possibly attract beetles to a suitable habitat [21]. It is also possible that pioneering beetles land randomly on trees and assess host quality upon contact [22]. However, apart from the few pioneering males, the aggregation pheromone attracts the majority of individuals to the host.

The attraction to the pheromone is modulated by other semiochemicals that appear in later attack phases. Verbenone and ipsenol are two such compounds that are believed to be used as cues to avoid heavily attacked trees [23]. In addition, volatiles that are particularly abundant in nonhost angiosperm plants (so called nonhost volatiles, NHV), such as green leaf volatiles (GLVs) [24] and compounds from the bark, such as C8-alcohols and trans-conophthorin [25, 26], have inhibitory effects on pheromone attraction. Combining these compounds with verbenone produces a strong synergistic effect and a potent antiattractant blend [27]. Possibly, the individual constituents in the synergistic blend represent different levels in the host selection sequence [6]. The GLVs that are common to broad-leaved plants may represent a signal of a nonhost dominated habitat. More specific plant volatiles, such as trans-conophthorin, may indicate nonhosts at the tree species level [7], whereas the antiattractive pheromone components may signal unsuitability of individual spruce trees.

\section{Olfactory Receptor Neurons of I. typographus and Other Bark Beetles}

Many compounds that are either attractants or antiattractants for conifer bark beetles have been identified $[3,6,7]$. Single-sensillum recordings from the ORNs of several bark beetle species have shown that many of the behaviorally active compounds elicit responses in different classes of neurons (Table 1). It is obvious that, except for I. typographus and the ambrosia beetle Trypodendron lineatum, more is known about ORN responses to pheromone components than about responses to plant odors (Table 1). In addition, several of the tested compounds (i.e., ipsdienol, ipsenol, verbenone, cis/trans-verbenol, exo-brecicomin, and $\alpha$-pinene) elicit strong responses in the majority of species studied. For more details on ORN specificity, sensitivity, and abundance in each species, the reader is referred to the cited literature.

Olfactory sensilla of $I$. typographus are present in three areas (or bands) on the antenna (Figure 2(a)) [41]. Andersson et al. [19] screened 150 olfactory sensilla for responses to an odor panel comprised of similar numbers of synthetic pheromone, host, and nonhost compounds. Strong excitatory responses were obtained from 106 ORNs; 45 responded specifically to various bark beetle pheromone compounds, 37 to host compounds, and 24 to antiattractive nonhost volatiles (NHVs). Based on response spectra, the 106 ORNs were grouped into 17 different classes (Figure 3). Additionally, 26 neurons (divided into 12 ORN classes) responded only weakly to any test odorant, indicating that the most potent compounds for these ORNs were lacking. In addition to the ORN classes described by Andersson et al. [19], three other classes, responding specifically to (+)-transverbenol, phenylethanol, or campher plus pino-camphone, respectively, had been identified previously (Table 1) [28]. Furthermore, the majority of the ORN classes responding to pheromone compounds was found in both studies. Many ORN classes have been subjected to dose-response trials that indicated that the ORNs, in general, are highly sensitive and specific for only one or a few structurally related pheromone or plant compounds (Figures 4(a)-4(c)) [19, 28]. Response thresholds for the best ligand(s) were normally found around 
TABLE 1: Compounds from different ecological sources that elicit strong responses in olfactory receptor neurons in eight species of Scolytinae.

\begin{tabular}{|c|c|c|c|c|}
\hline Species & $\begin{array}{l}\text { Beetle-produced } \\
\text { compounds }\end{array}$ & Host compounds & Nonhost compounds & References \\
\hline \multirow{11}{*}{ Ips typographus } & $(+)$-ipsdienol & Myrcene & Pine bark extract & \multirow{11}{*}[19,28-31]{} \\
\hline & (-)-ipsdienol & Campher (B) & Birch bark extract & \\
\hline & $(-)$-ipsenol & Pino-camphone (B) & 1-hexanol (D) & \\
\hline & $(-)$-cis-verbenol & p-cymene & E2-hexenol (D) & \\
\hline & $(+)$-trans-verbenol & 3 -carene & Z3-hexenol (D) & \\
\hline & $(-)$-verbenone & 1,8 -cineole & 1-octen-3-ol & \\
\hline & 2-methyl-3-buten-2-ol & $(+)$ - $\alpha$-pinene $(\mathrm{C})$ & 3-octanol & \\
\hline & Amitinol & $(-)$ - $\alpha$-pinene $(C)$ & $(S, S)$-trans-conophthorin $(\mathrm{A})$ & \\
\hline & Phenylethanol & & & \\
\hline & exo-brevicomin $(\mathrm{A})^{*}$ & & & \\
\hline & $( \pm)$-chalcogran $(\mathrm{A})$ & & & \\
\hline \multirow{6}{*}{ Ips pini } & (+)-ipsdienol & Linalool & & \multirow{6}{*}[29,32-34]{} \\
\hline & (-)-ipsdienol & Camphor & & \\
\hline & $( \pm)$-ipsenol & Myrcene & & \\
\hline & cis-verbenol & & & \\
\hline & trans-verbenol & & & \\
\hline & Verbenone & & & \\
\hline \multirow{3}{*}{ Ips paraconfusus } & $(+)$-ipsdienol & & & \multirow{3}{*}[33]{} \\
\hline & (-)-ipsdienol & & & \\
\hline & $( \pm)$-ipsenol & & & \\
\hline \multirow{8}{*}{ Dendroctonus pseudotsugae } & Frontalin & $\alpha$-pinene & & \multirow{8}{*}[35,36]{} \\
\hline & 3-methyl-2-cyclohexenone & Limonene & & \\
\hline & 3-methyl-2-cyclohexenol & & & \\
\hline & 1-methyl-2-cyclohexenol & & & \\
\hline & trans-verbenol & & & \\
\hline & cis-verbenol & & & \\
\hline & Verbenone & & & \\
\hline & Ipsenol & & & \\
\hline \multirow{5}{*}{ Dendroctonus frontalis } & $(-)$-frontalin & $\alpha$-pinene & & \multirow{5}{*}[37,38]{} \\
\hline & exo-brevicomin & 3-carene & & \\
\hline & endo-brevicomin & & & \\
\hline & Verbenone & & & \\
\hline & trans-verbenol & & & \\
\hline \multirow{2}{*}{ Dendroctonus micans } & $(+)$-ipsdienol & & & \multirow{2}{*}[31]{} \\
\hline & exo-brevicomin & & & \\
\hline \multirow{6}{*}{ Trypodendron lineatum } & $(+)$-lineatin & Ethanol & Pine bark extract & \multirow{6}{*}[39]{} \\
\hline & Phenylethanol & Methanol & Birch bark extract & \\
\hline & & Butanol & & \\
\hline & & $\alpha$-pinene & & \\
\hline & & $\beta$-pinene & & \\
\hline & & Spruce bark extract & & \\
\hline Tomicus destruens & & Compounds in pine extract & Benzyl alcohol & {$[40]$} \\
\hline
\end{tabular}

* Compounds that elicit responses of similar strength in the same ORN class are indicated by the same capital letter. Odorants eliciting secondary responses are omitted for clarity. 


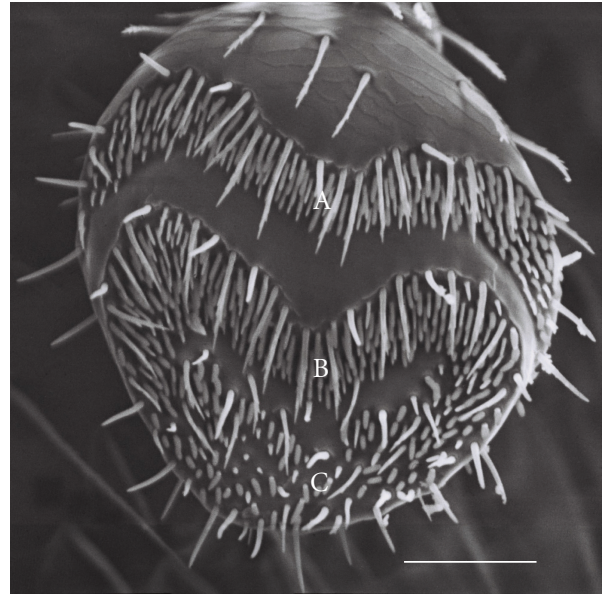

(a)

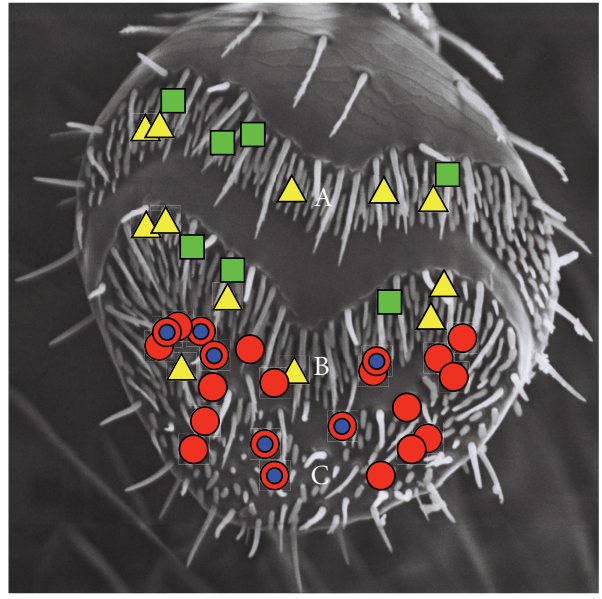

(b)

Figure 2: (a) Olfactory sensilla are present in three areas (A, B, and C) on the antennal club of Ips typographus. (b) Spatial distribution patterns of four classes of olfactory receptor neurons (ORNs). ORNs responding to green leaf volatile alcohols (nonhost) $=$ green squares, myrcene (host) = yellow triangles, cis-verbenol (pheromone) = red circles, 1,8-cineole (host) = blue small circles (from [19], with permission from the publisher). Scale bar $=50 \mu \mathrm{m}$.

the $1 \mathrm{ng}$ dose on the filter paper using paraffin oil as solvent [19]. A high specificity, not only among pheromone ORNs, but also among those for plant compounds, seems to be a general rule also in other bark beetle species (see especially $[32,35])$.

The ORNs of I. typographus are not randomly distributed on the antenna. Instead, ORNs from a particular class are generally found either in both the proximal and medial bands of sensilla, or exclusively in the distal area (Figure 2(b)) [19]. This distribution pattern seems to correspond to the distribution of the two morphological types of single-walled sensilla previously identified [41].

It is common in insects that the pheromone ORNs are numerous on the antenna and that the most common ORN type is tuned to the major (most abundant) component $[42,43]$. In I. typographus, the most recurrent ORN class was tuned to $(-)$-cis-verbenol [19]. In contrast, there were only few cells specific for 2-methyl-3-buten-2-ol (MB) (Figure 3) $[19,28]$, an essential pheromone component which is produced, and behaviorally active, in much larger quantities [20, 44]. This suggests that the pattern might be reversed in the bark beetle. However, the MB cells were found in a restricted area on the antenna [19], that is, on the borderline between the medial band and distal area of sensilla, which could have resulted in this cell type being underrepresented among the sampled sensilla. Alternatively, as MB is highly volatile, the low number of cells could be the result of the compound being lost from the stimulus cartridge upon stimulation. Indeed, photoionization detector measurements showed that the airborne amount of $\mathrm{MB}$ released from the stimulus pipette drops dramatically upon stimulation (Figure 5) [45]. However, the insect ORN still responded vigorously despite the low concentration, rendering this explanation unlikely. In contrast to Andersson et al. [19], Tømmerås [28] found that the ORNs tuned to ipsdienol were the most common ones

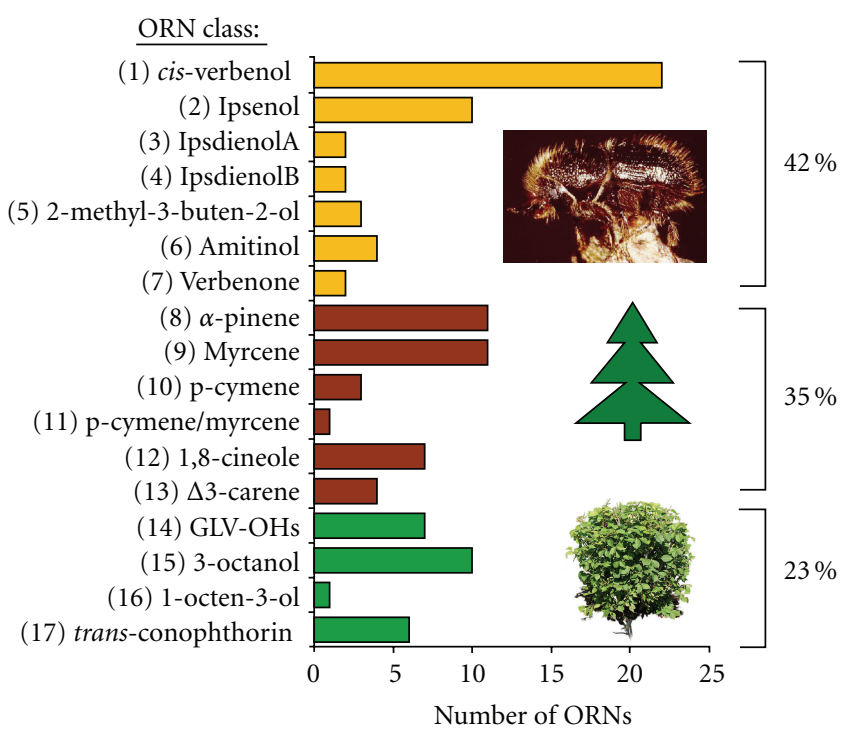

FIGURE 3: Number of olfactory receptor neurons (ORNs) of 17 strongly responding classes of Ips typographus (data from [19]). ORN classes are labeled according to which compound(s) elicited the strongest response. As pure enantiomers were not tested, it is likely that the ipdienol ORN classes $\mathrm{A}$ and $\mathrm{B}$ correspond to the ORNs responding to (+)- and (-)-ipdienol, respectively [29]. Orange $=$ bark beetle pheromone compounds, brown $=$ conifer compounds, green $=$ nonhost volatiles. GLV-OHs = green leaf volatile alcohols.

in I. typographus. This discrepancy may also be explained by the nonrandom localization of ORNs on the antenna (i.e., neurons for cis-verbenol are abundant only in the distal part of the antennae, Figure 2(b)).

Although no primary attraction has been demonstrated, the high frequency of ORNs tuned to conifer-related 


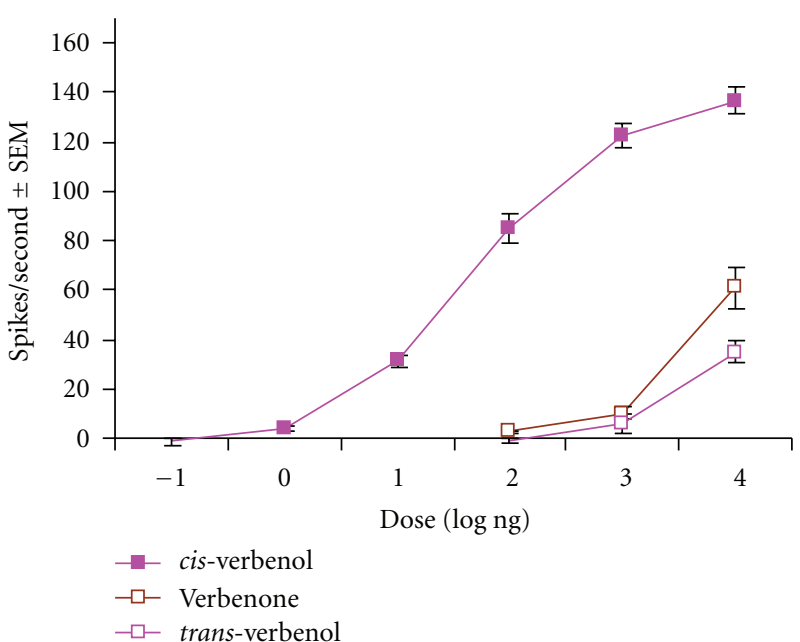

(a)

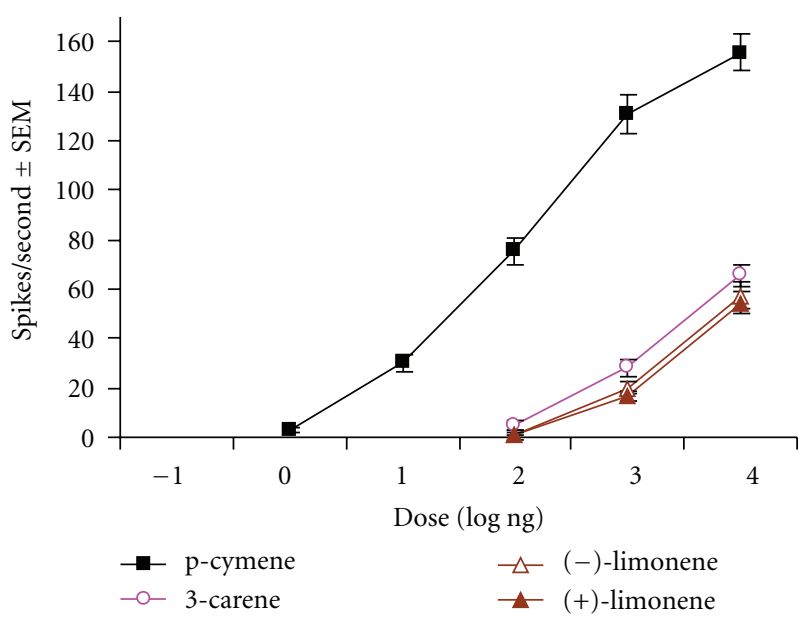

(c)

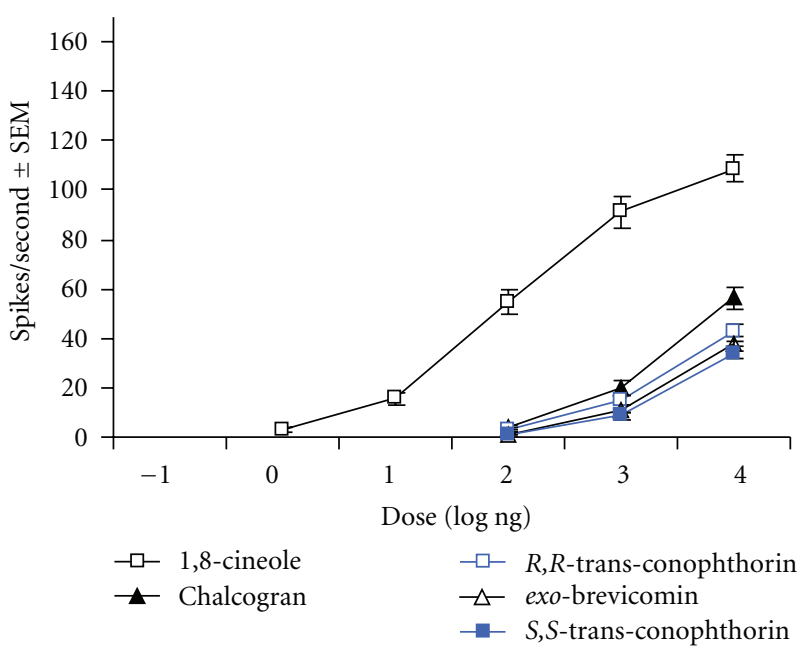

(b)

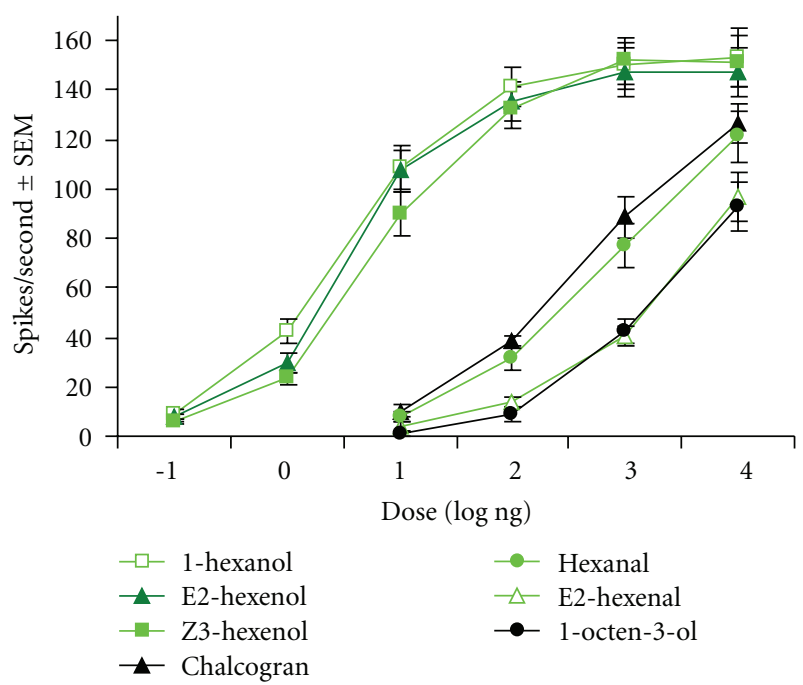

(d)

FIGURE 4: Dose-response curves from four receptor neuron classes of Ips typographus, demonstrating specific primary responses to (a) the pheromone component cis-verbenol, the spruce compounds (b) 1,8-cineole and (c) p-cymene. (d) Indiscriminate response to the three green leaf volatiles 1-hexanol, E2-hexenol, and Z3-hexenol (modified from [19], with permission from the publisher).

monoterpenes (Table 1, Figure 3) suggests that host kairomone is relevant for host location by I. typographus. As mentioned previously, these compounds may serve as habitat-scale attractants [21], or as modulators of pheromone attraction $[8,9]$. Perhaps the most striking finding from the bark beetle SSR studies is that almost $25 \%$ of the strongly responding ORNs were specifically tuned to antiattractive NHV (Table 1, Figure 3) [19]. This indicates that insects may devote a lot of olfactory capacity to the detection of compounds from sources that they avoid. Similar results have not been found in any other insect studied so far, however, it is likely that many other bark beetles that show strong GC-EAD responses to NHV also have a large proportion of ORNs tuned to such compounds [7, 46-48].

\section{Discrimination of Enantiomers}

Most bark beetle pheromone compounds are chiral. Attraction is typically evoked by only one of the enantiomers, while the other sometimes inhibits attraction (e.g., $[20,33])$. The enantiospecific behavioral response is reflected in the specificity of the ORNs detecting the compounds (Table 1). For instance, ORNs that are specific for either the (+)- or the (-)-enantiomer of ipsdienol, ipsenol, verbenone, or cisand trans-verbenol have been identified in several Ips species $[28,33]$. Other examples are the ORNs in the Southern pine beetle, $D$. frontalis [37], and in the Douglas-fir beetle, $D$. pseudotsugae [36], that discriminate between the $(+)$ - and (-)-enantiomer of frontalin (Table 1). 


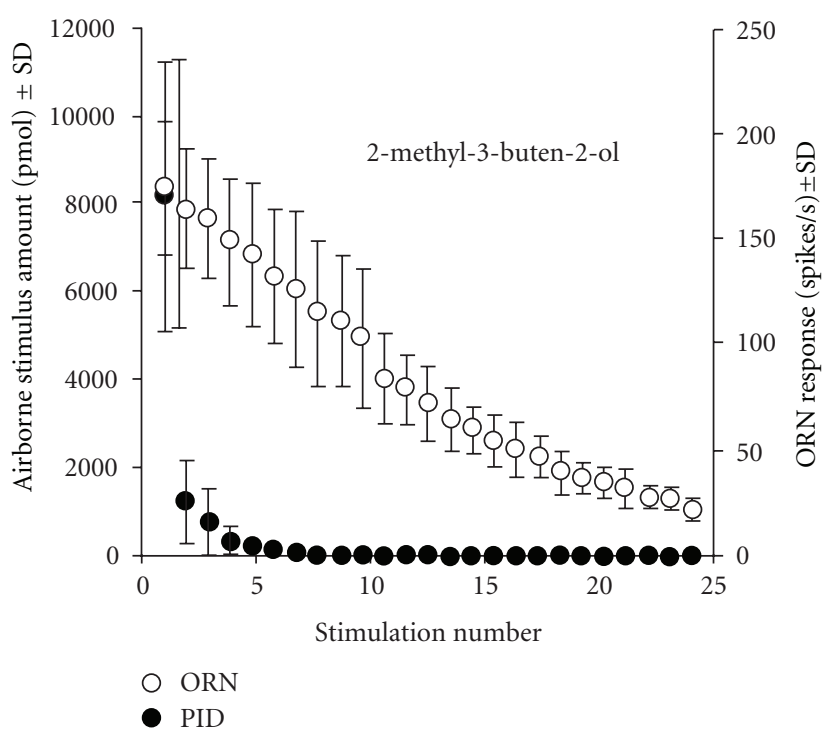

FIGURE 5: Response of Ips typographus olfactory receptor neurons (ORNs) and a photoionization detector (PID) to successive stimulations with 2-methyl-3-buten-2-ol $(N=4)$ (modified from [61]).

In general, the sensitivity of the pheromone ORNs seems to be $10-100$-fold higher for the enantiomer that they are tuned to, as compared to the other $[28,33]$. In addition, there seems to be a correspondence between the attraction to a specific enantiomer, and the frequency of ORNs on the antenna that responds to it. For instance, I. pini is attracted by (-)-ipsdienol and has more of its ORNs tuned to (-)ipsdienol than to (+)-ipsdienol. Similarly, I. paraconfusus, which is attracted by $(+)$-ipsdienol, has most of its ipsdienol ORNs tuned to the (+)-enantiomer [33].

Enantiospecific responses to plant compounds have been recorded in I. typographus [19]. The neuron class that responded most strongly to the nonhost volatile transconophthorin (Table 1) was $>100$-fold more sensitive to the $(5 S, 7 S)$-enantiomer than to the $(5 R, 7 R)$-enantiomer. In fact, other structurally related compounds (racemic exobrevicomin and chalcogran) elicited stronger responses in this ORN than did the $(5 R, 7 R)$-enantiomer of trans-conophthorin [19]. In another class of ORN, the naturally occurring (-)-1-octen-3-ol elicited a slightly stronger response than the racemic mixture, indicating that the (-)enantiomer is the key ligand. In contrast, the neuron that is tuned to $\alpha$-pinene responded similarly to both enantiomers (Table 1) [19].

\section{Olfactory Receptor Neuron Responses and Behavior}

The results that have been obtained from single sensillum recordings $[19,28]$ indicate that behavioral responses of $I$. typographus to several compounds can likely be explained by the responses of the ORNs.

Several volatiles from nonhost plants were previously shown to inhibit pheromone attraction of I. typographus
[24-26]. The three GLVs: 1-hexanol, E2-hexenol, and Z3hexenol all reduced pheromone attraction to a similar extent. However, combining the three did not produce a stronger inhibition of attraction, a phenomenon defined as redundancy [27]. Interestingly, the only ORN that was sensitive to any of these volatiles had a more or less identical sensitivity to all three of them (Table 1, Figure 4(d)) [19]. Thus, it appears as if the bark beetle cannot differentiate between the compounds at the physiological level, which agrees well with their behavioral redundancy. In contrast, the compounds verbenone and trans-conophthorin that synergize the inhibition are detected by different ORNs $[19,28]$. Interestingly, the pheromone component, chalcogran, of the sympatric Pityogenes chalcographus, was primarily detected, by I. typographus, by the same neuron as trans-conophthorin (Table 1). Chalcogran also inhibits pheromone attraction of I. typographus [49].

Most insects house their ORNs for pheromone compounds in sensilla that are distinct from the ones that detect plant compounds (e.g., $[50,51])$. However, in some sensilla in I. typographus, the ORN for the aggregation pheromone component cis-verbenol $(\mathrm{cV})$ is colocalized with an ORN that responds to the host plant compound 1,8-cineole (Ci) $[8,19]$ (Figure 2(b)). This lack of segregation between ORNs detecting pheromones and plant volatiles may suggest that host finding in bark beetles is an integrated process that involves both pheromones and plant volatiles. When the ORN for $\mathrm{Ci}$ responded, the colocalized $\mathrm{cV}$ cell was inhibited, indicative of interactions between ORNs in the periphery. In addition, $\mathrm{Ci}$ was found to be particularly abundant in heavily attacked spruce trees and the compound strongly reduced pheromone attraction (88\% reduction in trap catch) in the field [8]. Possibly, $\mathrm{Ci}$ is a signal of an unsuitable (crowded) host or a well-defended tree.

\section{Peripheral Modulation of ORN Responses}

Colocalization of insect ORNs in the same sensillum is thought to improve coincidence detection, which increases the insect's spatiotemporal resolution of odor signals [52] and improves ratio detection of ecologically relevant odor mixtures [53]. In addition, the presence of two or more neurons in the same sensillum may provide opportunities for signal modulation in the periphery. Indeed, in the Douglas-fir beetle, Dendroctonus pseudotsugae, two ORNs, each specific for one of the two pheromone components 3-methyl-2-cyclohexenone or 3-methyl-2-cyclohexenol, are colocalized. When either one of the ORNs responded to its specific ligand, the spontaneous activity of the other ORN was reduced. This observation indicated reciprocal interactions, either directly between the two neurons, or between the two ligands and their respective receptors [35]. In addition, when another ORN type that responded to limonene (10 ng dose) was challenged with a binary mixture of limonene and 3-methyl-2-cyclohexenol (10:1000 ng), the response to limonene was completely shut down [35].

In I. typographus, not all $\mathrm{cV}$ neurons (large amplitude Acell) are colocalized with the neuron for $\mathrm{Ci}$ (small amplitude B-cell) (Figure 6(a)). These $\mathrm{cV}$ neurons are instead found 

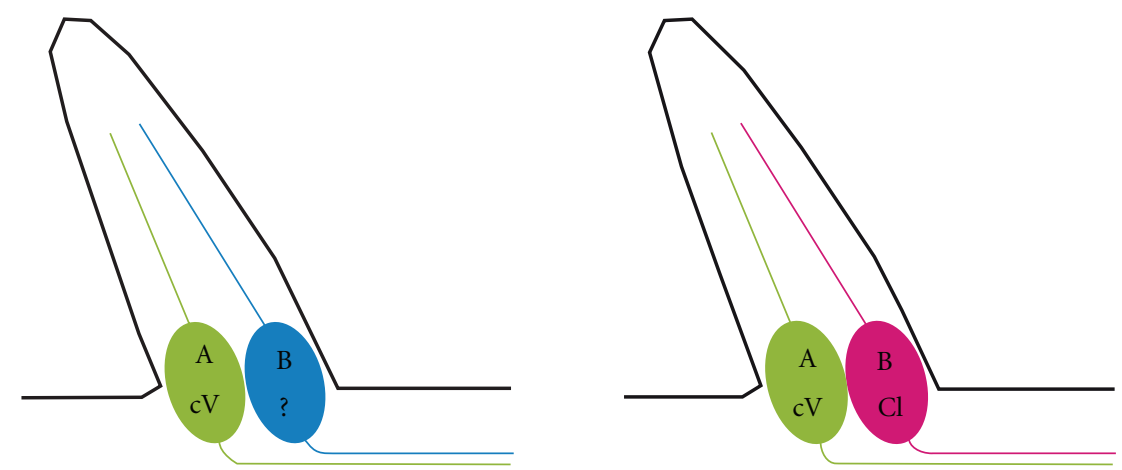

(a)

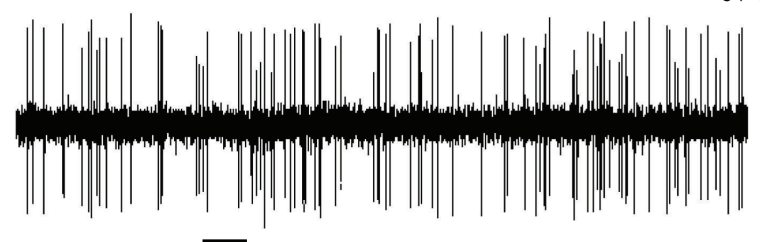

$\mathrm{cV} 1 \mathrm{ng}$
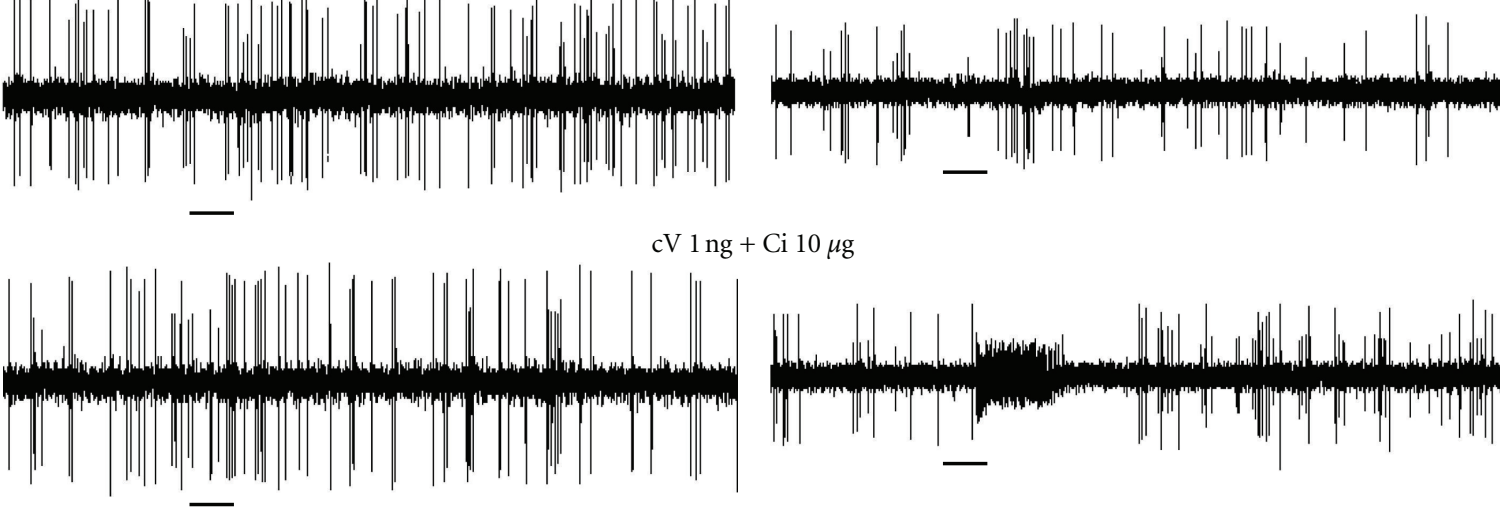

(b)
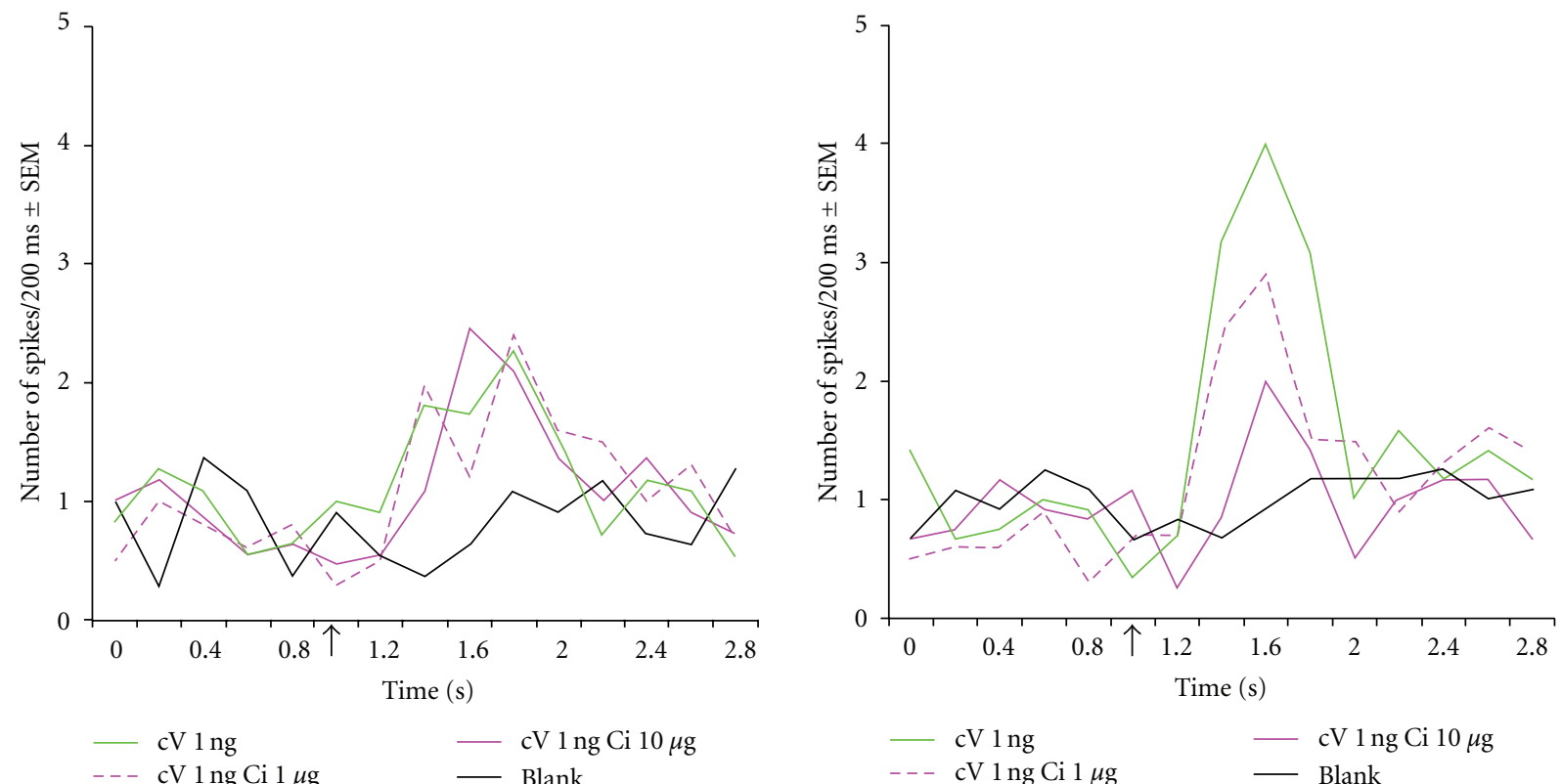

(c)

Figure 6: (a) Schematic drawing of the two types of sensilla in Ips typographus containing the A cell (large amplitude spikes) for cis-verbenol $(\mathrm{cV})$, accompanied either by a nonresponsive (left column) B cell (small amplitude), or a B cell for 1,8-cineole (Ci) (right column). (b) Responses of both sensillum types to $1 \mathrm{ng} \mathrm{cV}$ (upper traces), and a binary mixture of $1 \mathrm{ng} \mathrm{cV}$ and $10 \mu \mathrm{g}$ Ci (lower traces). Note the inhibition of the $\mathrm{cV}$ response during the response to $\mathrm{Ci}$ in the $\mathrm{B}$ cell. Black horizontal bars indicate the $0.5 \mathrm{~s}$ stimulation period. (c) Detailed response curves to $\mathrm{cV}$ and binary $\mathrm{cV}$ : $\mathrm{Ci}$ mixtures showing a $\mathrm{Ci}$ dose-dependent inhibition of the $\mathrm{cV}$ response only in sensilla that also contain the $\mathrm{Ci}$ cell $(N=10-12)$. Arrows indicate the onset of the $0.5 \mathrm{~s}$ stimulation period (modified from [8], with permission from the publisher). 
together with another ORN type that does not respond to any odorant tested so far [19]. The Ci inhibited the cV cell only in sensilla in which the two neurons were colocalized, implying that the inhibition might be due to interactions between the ORNs. To test this hypothesis, Andersson et al. [8] recorded both types of $\mathrm{cV}$ sensilla (with or without the $\mathrm{Ci}$ cell) and tested responses to binary $\mathrm{cV} / \mathrm{Ci}$ mixtures. They found that not only the spontaneous activity but also the ORN response to the lowest $\mathrm{cV}$ dose $(1 \mathrm{ng})$ was inhibited by simultaneous stimulation with high doses of $\mathrm{Ci}(1-10 \mu \mathrm{g})$. This inhibition occurred only in sensilla that also contained the Ci cell (Figures 6(b)-6(c)). In addition, the response to the higher $\mathrm{cV}$ dose (10 ng) was more strongly inhibited in sensilla where the $\mathrm{Ci}$ cell was colocalized. Thus, it seems plausible that the two ORNs interact, possibly by means of passive electrical interactions [54]. However, if or to which extent the reduction in pheromone trap catches by the presence of $\mathrm{Ci}$ [8] can be explained by the inhibition of the $\mathrm{cV}$ ORN remains unknown, as the excitatory input from the two ORNs provides the means also for central integration [55]. It seems like similar inhibitory interactions between colocalized ORNs occur also in other insects [51, 56, 57], but the phenomenon has so far only been systematically addressed in bark beetles.

\section{Difficulties in Comparing ORN Responses to Compounds with Different Volatility}

In most SSR studies, odor stimuli are prepared based on a known amount (e.g., in nano- or microgram) of compound applied to a piece of filter paper that is positioned inside a Pasteur pipette odor cartridge. Upon stimulation, the headspace in the cartridge is blown over the insect preparation. Depending on compound, solvent, and how many times the cartridge has been used, the quantity of molecules reaching the insect can be highly variable and seriously affect the ORN response [58, 59]. Indeed, different stimulation regimes, compound doses, and solvents (mostly hexane and paraffin oil) have been used in the various bark beetle SSR studies (Table 1), making it difficult to directly compare the sensitivity and specificity of ORNs characterized in different species or studies. Furthermore, the physical parameters of the odor-delivery system also affect the integrity of an airborne odor stimulus [60], which may further increase the variability among responses.

Airborne amounts of different compounds have been measured with a photoionization detector [45]. A huge variation among compounds was observed. For the most volatile compounds, such as 2-methyl-3-buten-2-ol (Figure 5), ca $80 \%$ of the headspace in the odor cartridge was lost at the first puff, even though paraffin oil was used as solvent. Airborne amounts of heavier compounds, such as linalool, were reduced by only ca $50 \%$ after 50 reiterative stimulations. In addition, compounds that were dissolved in pentane were released at a much higher rate than compounds in paraffin [45].

The large variation between compounds, solvents, and successive stimulations could easily bias electrophysiological responses in insects. This was verified by reanalyzing the response of the 3-octanol ORN of I. typographus [19] to two C8-alcohols (3-octanol and 1-octen-3-ol) and two C6-alcohols (Z3-hexenol and 1-hexanol) using both fresh (not used) and "old" (used 10 times) stimulus pipettes [45]. The ORN response to fresh pipettes was clearly different from the response to the "old" pipettes. In particular the response to the C6-alcohols was clearly lower when old pipettes were used. In fact, the difference in response was so large that it falsely implied that recordings were made from two distinct ORN classes. Such a finding suggests that it is absolutely necessary to use very strict experimental protocols for electrophysiological recordings, and that it sometimes is required to measure airborne odor amounts, especially when compounds of different volatility are used as stimuli [45].

\section{Odor Coding in Bark Beetles Compared to Other Insects}

In insects in general, neurons that detect pheromone constituents have a narrow tuning. Bark beetles are no exception as the ORNs that respond to aggregation pheromone compounds are, in most cases, sensitive to only one compound. The tuning width of insect ORNs detecting plant volatiles seems to range from narrow to broad, although ORN specificity is strongly correlated to the stimulus concentration tested [18]. Most of the ORNs for plant volatiles in I. typographus are narrowly tuned [8]. However, some show more indiscriminate responses, such as the GLV neuron that had similar sensitivity to 1-hexanol, E2-hexenol, and Z3-hexenol. This is in contrast to the highly specific GLV neurons that have been described in, for instance, scarab beetles $[50,51]$, and in the Colorado potato beetle [62]. The difference may be related to the fact that these other species feed on angiosperms, which presumably requires a better resolution of angiosperm dominated volatiles (i.e., GLVs) than what is needed for a conifer specialist. Many of the bark beetle ORNs are highly selective for specific enantiomers, both in terms of pheromones and plant compounds. However, this feature is not unique for bark beetles; highly enantioselective neurons have been characterized also in other insects [63-65]. In contrast, no other insect studied so far has a comparable frequency of ORNs tuned to antiattractants as the one found in I. typographus [19].

The co-localization of ORNs for pheromone and plant compounds in I. typographus is not commonly found in insects. This special type of ORN pairing may be related to the fact that host colonization in bark beetles often involves both pheromone and plant-produced compounds [8]. In addition, the colocalized neurons for plant and pheromone compounds also interacted by inhibiting their neighboring neuron while responding [8]. It is difficult to say whether a similar interaction occurs also in other insects, since it has not been systematically addressed elsewhere. However, inhibition of the spontaneous activity of the large-spiking cell when the small-spiking cell responds seems to be a common phenomenon $[35,51,56,57]$, indicating that the same type of modulation could be present. Indirect evidence for ORN interactions was found previously in the honeybee [66]. The 18-35 ORNs that are housed within honeybee 


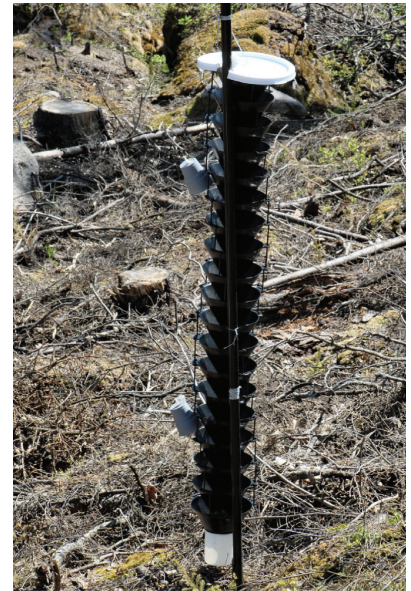

(a)

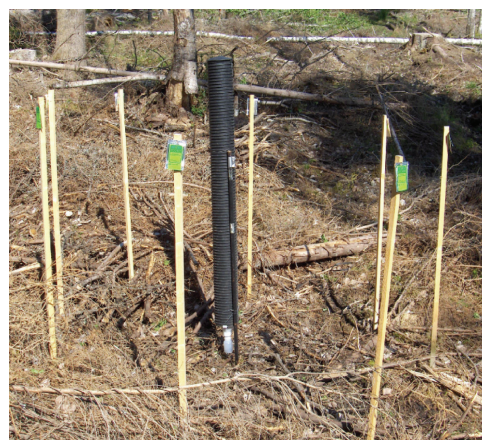

(c)

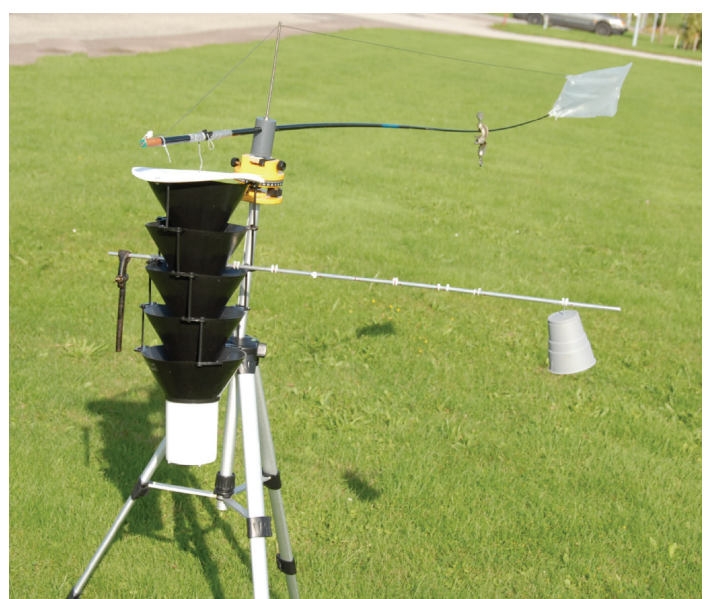

(b)

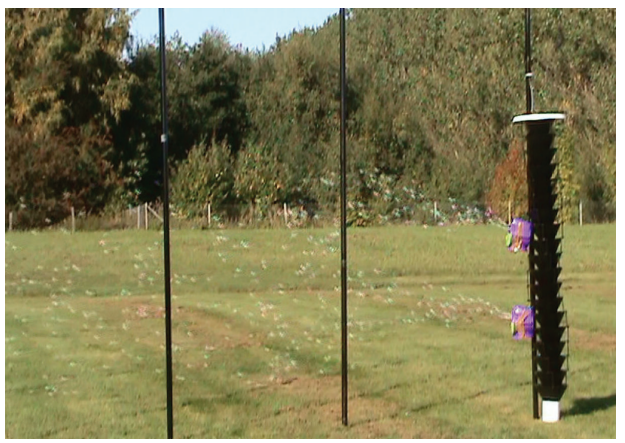

(d)

Figure 7: (a) Lindgren funnel traps (19-funnel size) were used in the vertical spacing tests with Ips typographus. Dispensers positioned under grey cups. (b) A Lindgren trap (5-funnel size) was attached to a wind vane in the horizontal spacing tests to ensure constant distance between plumes. (c) Pipe trap surrounded by eight nonhost volatile dispensers in the antiattractant background tests. (d) Soap bubble visualization of vertical plume overlap at a spacing distance of $48 \mathrm{~cm}$. Distance between black poles $=1 \mathrm{~m}$ (modified from [61]).

sensilla placodea seemed to respond to odors in a coordinated manner, indicating that the individual ORNs do not act as independent response units. However, in that study, it was not possible to keep track of the individual ORNs.

Taken together, odor coding in bark beetles is, in general, similar to odor coding in other insects, but it also exhibits some rare features. The coding principle seems to be consistent with the "combinatorial code" theory, but the olfactory input travels mainly through highly specific channels.

\section{Detection and Behavior in Odor-Diverse Habitats}

Activation of an ORN by an attractant may cause an upwind flight by the insect towards the odor source. However, if repulsive compounds simultaneously trigger other ORNs to fire, the upwind flight may be aborted. Thus, in environments with a high "semiochemical diversity" [27] where odor plumes from different sources intermix, localization of host plants may be hampered by the presence of odors from nonhosts $[67,68]$. Thus, for bark beetles, it may be possible to reduce the risk of attacks by making the environment more semiochemically diverse. Homogenous mixing of odor plumes from different sources is, however, contradicted by the partitioning of plumes into "odor packages" (or filaments) that are interspersed with pockets of "clean air" $[11,12]$. This, in turn, is thought to facilitate plume discrimination by insects.

Placing an NHV mixture inside a pheromone trap, that is, next to the pheromone bait, greatly reduces trap catch of I. typographus [27]. However, to test the "semiochemical diversity hypothesis," pheromone trap catches in the presence of NHV at different vertical and horizontal distances from the pheromone dispenser (Figures 7(a)-7(b)), were investigated [69]. Trap catches in response to separated pheromone components (cis-verbenol and 2-methyl3-buten-2-ol) were also tested (in the absence of NHV) to further investigate responses to separated baits in general. In addition, the response of the beetle was compared to the response of the Egyptian cotton leaf worm, Spodoptera littoralis (Lepidoptera: Noctuidae), to separated sex pheromone components and to separated pheromone and behavioral antagonist. In both species, increased spacing between pheromone and antiattractants led to increased trap catch, whereas, as expected, increased spacing between pheromone components had the opposite effect. However, 


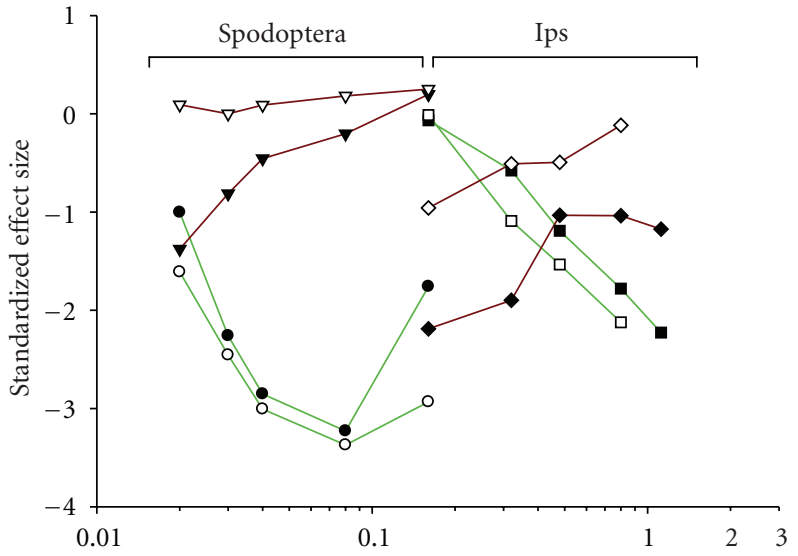

Spacing exp:

$\rightarrow-$ Spod. Ph-ant low dose

$\checkmark$ Spod. Ph-ant high dose

- Spod. Ph major compound in

- - Spod. Ph major compund out

- Ips Ph vertical

- - Ips Ph horizontal

$\diamond$ Ips Ph-NHV horizontal

$\prec$ Ips Ph-NHV vertical

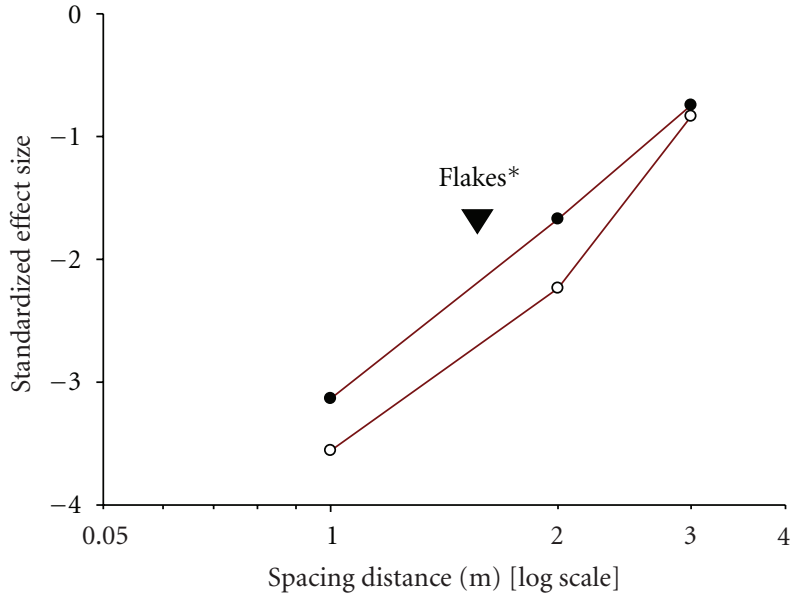

Background exp:

- Ips IT-REP low dose

- - Ips IT-REP high dose

FIGURE 8: (a) The effect of spacing between attractant and antiattractant sources on trap catches of Ips typographus and Spodoptera littoralis, illustrated by measures of effect size (Hedges' unbiased $g$ ). The effect size provides a measure of a biological treatment effect by scaling the difference between the treatment and the control means, with the pooled standard deviation for those means. Effect sizes further from zero than 0.8 are regarded as strong effects. In all experiments, the pheromone bait alone (zero distance between components) was the control. The zero $\mathrm{cm}$ spacing distance in experiments involving antiattractants is omitted for clarity. (b) Effect sizes in the Ips antiattractant background experiments using nonhost volatile dispensers at eight positions, or flakes around the trap. * Flakes were evenly distributed on the ground 0-2 $\mathrm{m}$ from the trap. Thus, this treatment is "not to scale" on the $x$-axis. $\mathrm{Ph}=$ pheromone; Ant $=$ Spodoptera pheromone antagonist; NHV = nonhost volatiles; IT-REP = semicommercial Ips typographus repellent dispenser (from [69], with permission from the publisher).

the two species differed greatly with respect to the spacing distances that affected their trap catch (Figure 8(a)). While beetle trap catches were affected by separation of some decimeters, trap catches of the moth were affected by separation distances of just a few centimeters [69]. In each species, the spacing distances affecting trap catch did not differ between the pheromone component spacing and the pheromone/antiattractant spacing experiments [69].

The bark beetle pheromone/NHV spacing experiments indicated antiattractive effects of NHV up to a distance of $>1 \mathrm{~m}$ [69]. To further investigate potential effects of NHV at even longer distances, pheromone attraction was studied in the presence of a synthetic background of NHV, either created by eight NHV point sources positioned in a ring (with 1,2 , or $3 \mathrm{~m}$ radius) around a central pheromone trap (Figure $7(\mathrm{c})$ ), or by ca 6000 small (ca $3 \times 3 \mathrm{~mm}$ ) NHV impregnated flakes [70] on the ground around a pheromone trap [69]. With the eight NHV sources, bark beetle attraction was reduced up to the $2 \mathrm{~m}$ spacing distance, and there was still a tendency for reduced attraction at the $3 \mathrm{~m}$ distance (Figure 8(b)). Similar to the eight point sources, the NHV flakes also reduced pheromone attraction [69]. The active spacing distances are in accordance with the "active inhibitory range" of NHV of at least $2 \mathrm{~m}$ that was estimated previously [27]. The pheromone dose used by Andersson et al. [69] was comparable to that released from a mass-attacked tree, which is a very strong signal. Thus, it is striking that volatiles from nonhost plants can inhibit attraction when they are released a few meters away from the pheromone source. This indicates that avoiding not only nonhost species, but also nonhost habitats, likely improves bark beetle fitness.

The different spacing distances that affected trap catches of the beetle and the moth may reflect differences in the size of the natural odor sources (and plumes) the insects orient to [69]. While a male moth orients towards a single calling female, bark beetles may orient to large patches of trees with hundreds of calling males. Furthermore, the moth sex pheromone communication system is highly specialized. A male moth flies towards a calling female for mating only, whereas the bark beetle aggregation pheromone can be used as a signal of mates, food, and oviposition sites. Thus, the different selection pressures that operate on these systems have likely resulted in different degrees of specialization. The ORNs for pheromone compounds in moths are housed in specific sensilla (trichodea), distinct from the ones that 
detect plant odors [43]. In contrast, I. typographus groups the cis-verbenol pheromone ORN together in the same sensilla as the ORN for the plant compound 1,8-cineole, although the ORNs themselves are specific in their response [8].

Similar to I. typographus, studies on Dendroctonus bark beetles indicated synergistic interactions between pheromone components when two baits were separated by several meters [71, 72]. The sharp response of $S$. littoralis to odor source spacing has been observed previously in other moths [73-75]. The most extreme example is provided by Fadamiro et al. [52], who found that $1 \mathrm{~mm}$ separation between pheromone and antagonist was sufficient to restore upwind flight to the pheromone by male Helicoverpa zea. It was hypothesized that coincident detection of pheromone components and antagonists, achieved by colocalization of the ORNs, was the reason for this amazing ability of the males. Furthermore, synchronous detection of pheromone compounds was shown to improve the temporal spiking pattern by projection neurons in the antennal lobe of Manduca sexta moths [76]. Thus, it is clear that coincidence detection is of great importance in the pheromone system of moths. Soap bubble generators were used to visualize plume overlap at the different spacing distances used for I. typographus (Figure 7(d) ) [69]. The simulations indicated that filaments from different plumes are more likely to overlap and, thus, to be detected coincidently, when the sources are close to each other. Therefore, the lower sensitivity of I. typographus to small-scale spatial separation of odor sources might indicate that coincidence detection is of less importance for bark beetles than for moths [69].

\section{Applications}

Conifer pest insect infestations are typically less common in diversified habitats [67], which in part may be due to the presence of antiattractive NHV. The finding that NHV, from a distance of at least $2 \mathrm{~m}$ (see also [27]), can reduce attraction to a pheromone dose comparable to that released from a mass-attacked tree suggests a potential for NHV in forest protection. However, pheromone attraction was not completely shut down so it is more likely that, instead of counteracting ongoing mass attacks, synthetic or natural NHV sources may reduce the risk of spruces being attacked in the first place. Indeed, spruces were previously protected by NHV dispensers attached to every second tree, demonstrating a protective effect of ca $2 \mathrm{~m}$ [77]. In another study, groups of ten trees were all protected by 20 NHV dispensers, and bark beetle attacks were diverted to trees $>15 \mathrm{~m}$ away [78].

In addition, the spruce compound 1,8-cineole that strongly reduced pheromone attraction should be further tested in combination with the other active semiochemicals for possible improvement of antiattractant blends. It is possible that the repression of the ORN for cis-verbenol by 1,8 cineole, adds another inhibitory mechanism by distorting the "perceived blend ratio" of the aggregation pheromone. If so, it is likely that a more effective antiattractant blend can be obtained than the one that is comprised of GLV alcohols, C8alcohols, trans-conophthorin, and verbenone [27].

\section{Conclusions and Future Directions}

The recent advances in bark beetle olfactory physiology have provided a connection between the physiological and behavioral responses of I. typographus to ecologically relevant compounds. This connection has allowed for a deeper understanding about how bark beetles (and possibly insects in general) may encode, and respond to, the odor environment. However, there are still several ORNs of I. typographus (and other species) for which odor ligands have not been identified, meaning that there is yet more to be learned about its olfactory physiology. Identification of active compounds should be achieved by GC-coupled SSR and by testing headspace collections from, for instance, attacked and unattacked or resistant host trees.

At the molecular level, Andersson and collaborators $[61,79]$ recently sequenced the antennal transcriptome of $I$. typographus, leading to identification of gene sequences for 40 different candidate olfactory receptors (ORs). The amino acid sequences of the receptors were compared, in a sequence similarity tree, with receptors that were previously identified from the genome of the flour beetle, Tribolium castaneum. Many of the Ips ORs formed a bark beetle-specific branch, indicating an extension of OR function. Possibly, these receptors detect conifer-related volatiles or pheromones that are especially relevant for bark beetles. The other ORs of Ips were grouped together with ORs of T. castaneum, which may indicate conserved functionality of some sets of ORs within Coleoptera. Functional studies to reveal which compounds the ORs of Ips bind will be the next step in the study. Such studies will hopefully extend the connection from behavior, through physiology, all the way to the level of the receptor and gene.

The identification of the bark beetle ORs paves the way for the development of potential novel management strategies in the future. If the receptors for pheromone components and antiattractive NHV can be identified, it might be possible to identify ligands that pharmacologically block the pheromone receptors or hyperstimulate [80] receptors for nonhost volatiles. If such compounds are found, they might be dispensed in the forest to disrupt bark beetle pheromone communication and host tree localization.

One hypothesis why insect colocalize specific ORNs in the same sensilla is that it allows for improved spatiotemporal resolution of odor stimuli [52]. This hypothesis could be tested by comparing trap catches of I. typographus in response to spacing between pheromone and 1,8-cineole (ORNs for cis-verbenol and 1,8-cineole co-localized), with trap catches in response to spacing between pheromone and verbenone, the latter compound being detected by an ORN that is never colocalized with an aggregation pheromone neuron. Predictably, the beetle should be more "sensitive" to small-scale spacing between pheromone and 1,8-cineole than to spacing between pheromone and verbenone.

In order to put the sensory physiology into a more natural context, a portable single sensillum recording device [81] should be used in the field. The sensillum that contains the ORNs for cis-verbenol and 1,8-cineole could be used as a biological detector for measurements of plume filament 
overlap. Such measurements would reveal whether filaments from overlapping plumes are detected coincidently or not. It would also provide some indirect clue if beetles temporally integrate filaments from different plumes to a larger degree than moths, which could explain the difference in response to spacing in the two types of insects.

\section{Acknowledgments}

The author is grateful to Professor Fredrik Schlyter (SLU, Alnarp) for useful criticism on a previous manuscript draft. Funding was provided by FORMAS Project no. 230-20051778 "Semiochemical diversity and insect dynamics," the Linnaeus program "Insect chemical ecology, ethology, and evolution (ICE3)," and by the Department of Plant Protection Biology, SLU, Alnarp.

\section{References}

[1] W. A. Kurz, C. C. Dymond, G. Stinson et al., "Mountain pine beetle and forest carbon feedback to climate change," Nature, vol. 452, no. 7190, pp. 987-990, 2008.

[2] L. Stauffer, F. Lakatos, and G. M. Hewitt, "Phylogeography and postglacial colonization routes of Ips typographus $\mathrm{L}$. (Coleoptera, Scolytidae)," Molecular Ecology, vol. 8, no. 5, pp. 763-773, 1999.

[3] J. A. Byers, "Chemical ecology of bark beetles in a complex olfactory landscape," in Bark and Wood Boring Insects in Living Trees in Europe, a Synthesis, F. Lieutier, K. R. Day, A. Battisti, J.-C. Grégoire, and H. F. Evans, Eds., pp. 89-134, Kluwer Academic Publishers, Dordrecht, The Netherlands, 2004.

[4] B. Økland and O. N. Bjørnstad, "Synchrony and geographical variation of the spruce bark beetle (Ips typographus) during a non-epidemic period," Population Ecology, vol. 45, no. 3, pp. 213-219, 2003.

[5] B. Økland and O. N. Bjørnstad, "A resource-depletion model of forest insect outbreaks," Ecology, vol. 87, no. 2, pp. 283-290, 2008.

[6] F. Schlyter and G. A. Birgersson, "Forest beetles," in Pheromones of Non-Lepidopteran Insects Associated with Agricultural Plants, J. Hardie and A. K. Minks, Eds., pp. 113-148, CAB International, Oxford, UK, 1999.

[7] Q.-H. Zhang and F. Schlyter, "Olfactory recognition and behavioural avoidance of angiosperm nonhost volatiles by conifer-inhabiting bark beetles," Agricultural and Forest Entomology, vol. 6, no. 1, pp. 1-19, 2004.

[8] M. N. Andersson, M. C. Larsson, M. Blaženec, R. Jakuš, Q.-H. Zhang, and F. Schlyter, "Peripheral modulation of pheromone response by inhibitory host compound in a beetle," Journal of Experimental Biology, vol. 213, no. 19, pp. 3332-3339, 2010.

[9] N. Erbilgin, P. Krokene, T. Kvamme, and E. Christiansen, "A host monoterpene influences Ips typographus (Coleoptera: Curculionidae, Scolytinae) responses to its aggregation pheromone," Agricultural and Forest Entomology, vol. 9, no. 2, pp. 135-140, 2007.

[10] J. A. Byers and Q.-H. Zhang, "Chemical ecology of bark beetles in regard to search and selection of host trees," in Recent Advances in Entomological Research, T.-X. Liu and L. Kang, Eds., pp. 91-113, Higher Education Press, Beijing, China, 2010.

[11] N. J. Vickers, "Mechanisms of animal navigation in odor plumes," Biological Bulletin, vol. 198, no. 2, pp. 203-212, 2000.
[12] R. T. Cardé and M. A. Willis, "Navigational strategies used by insects to find distant, wind-borne sources of odor," Journal of Chemical Ecology, vol. 34, no. 7, pp. 854-866, 2008.

[13] J. Murlis, M. A. Willis, and R.T. Cardé, "Spatial and temporal structures of pheromone plumes in fields and forests," Physiological Entomology, vol. 25, pp. 211-222, 2000.

[14] L. Abuin, B. Bargeton, M. H. Ulbrich, E. Y. Isacoff, S. Kellenberger, and R. Benton, "Functional architecture of olfactory ionotropic glutamate receptors," Neuron, vol. 69, no. 1, pp. 44-60, 2011.

[15] L. B. Vosshall and R. F. Stocker, "Molecular architecture of smell and taste in Drosophila," Annual Review of Neuroscience, vol. 30, pp. 505-533, 2007.

[16] M. de Bruyne and T. C. Baker, "Odor detection in insects: volatile codes," Journal of Chemical Ecology, vol. 34, no. 7, pp. 882-897, 2008.

[17] L. B. Vosshall and B. S. Hansson, "A unified nomenclature system for the insect olfactory coreceptor," Chemical Senses, vol. 36, no. 6, pp. 497-498, 2011.

[18] E. A. Hallem and J. R. Carlson, "Coding of odors by a receptor repertoire," Cell, vol. 125, no. 1, pp. 143-160, 2006.

[19] M. N. Andersson, M. C. Larsson, and F. Schlyter, "Specificity and redundancy in the olfactory system of the bark beetle Ips typographus: single-cell responses to ecologically relevant odors," Journal of Insect Physiology, vol. 55, no. 6, pp. 556-567, 2009.

[20] F. Schlyter, G. Birgersson, J. A. Byers, J. Löfqvist, and G. Bergström, "Field response of spruce bark beetle, Ips typographus, to aggregation pheromone candidates," Journal of Chemical Ecology, vol. 13, no. 4, pp. 701-716, 1987.

[21] M. Saint-Germain, C. M. Buddle, and P. Drapeau, "Primary attraction and random landing in host-selection by woodfeeding insects: a matter of scale?" Agricultural and Forest Entomology, vol. 9, no. 3, pp. 227-235, 2008.

[22] J. A. Byers, "An encounter rate model of bark beetle populations searching at random for susceptible host trees," Ecological Modelling, vol. 91, no. 1-3, pp. 57-66, 1996.

[23] F. Schlyter, G. Birgersson, and A. Leufvén, "Inhibition of attraction to aggregation pheromone by verbenone and ipsenol - Density regulation mechanisms in bark beetle Ips typographus," Journal of Chemical Ecology, vol. 15, no. 8, pp. 2263-2277, 1989.

[24] Q.-H. Zhang, F. Schlyter, and P. Anderson, "Green leaf volatiles interrupt pheromone response of spruce bark beetle, Ips typographus," Journal of Chemical Ecology, vol. 25, no. 12, pp. 2847-2861, 1999.

[25] Q.-H. Zhang, F. Schlyter, and G. Birgersson, "Bark volatiles from nonhost angiosperm trees of spruce bark beetle, Ips typographus (L.) (Coleoptera: Scolytidae): chemical and electrophysiological analysis," Chemoecology, vol. 10, no. 2, pp. 69$80,2000$.

[26] Q.-H. Zhang, T. Tolasch, F. Schlyter, and W. Francke, "Enantiospecific antennal response of bark beetles to spiroacetal $(E)$ conophthorin," Journal of Chemical Ecology, vol. 28, no. 9, pp. 1839-1852, 2002.

[27] Q.-H. Zhang and F. Schlyter, "Redundancy, synergism, and active inhibitory range of non-host volatiles in reducing pheromone attraction in European spruce bark beetle Ips typographus," Oikos, vol. 101, no. 2, pp. 299-310, 2003.

[28] B. A. Tømmerås, "Specialization of the olfactory receptor cells in the bark beetle Ips typographus and its predator Thanasimus formicarius to bark beetle pheromones and host tree volatiles," Journal of Comparative Physiology A, vol. 157, no. 3, pp. 335$341,1985$. 
[29] H. Mustaparta, B. Å. Tømmerås, P. Baeckström, J. M. Bakke, and G. Ohloff, "Ipsdienol-specific receptor cells in bark beetles: structure-activity relationships of various analogues and of deuterium-labelled ipsdienol," Journal of Comparative Physiology A, vol. 154, no. 4, pp. 591-595, 1984.

[30] B. A.. Tømmerås and H. Mustaparta, "Chemoreception of host volatiles in the bark beetle Ips typographus," Journal of Comparative Physiology A, vol. 161, no. 5, pp. 705-710, 1987.

[31] B. A.. Tømmerås, H. Mustaparta, and J. C. Gregoire, "Receptor cells in Ips typographus and Dendroctonus micans specific to pheromones of the reciprocal genus," Journal of Chemical Ecology, vol. 10, no. 5, pp. 759-770, 1984.

[32] H. Mustaparta, M. E. Angst, and G. N. Lanier, "Specialization of olfactory cells to insect-and host-produced volatiles in the bark beetle Ips pini (say)," Journal of Chemical Ecology, vol. 5, no. 1, pp. 109-123, 1979.

[33] H. Mustaparta, M. E. Angst, and G. N. Lanier, "Receptor discrimination of enantiomers of the aggregation pheromone ipsdienol, in two species of Ips," Journal of Chemical Ecology, vol. 6, no. 3, pp. 689-701, 1980.

[34] H. Mustaparta, M. E. Angst, and G. N. Lanier, "Responses of single receptor cells in the pine engraver beetle, Ips pini (SAY) (Coleoptera: Scolytidae) to its aggregation pheromone, ipsdienol, and the aggregation inhibitor, ipsenol," Journal of Comparative Physiology. A, vol. 121, no. 3, pp. 343-347, 1977.

[35] J. C. Dickens, T. L. Payne, L. C. Ryker, and J. A. Rudinsky, "Single cell responses of the Douglas-fir beetle, Dendroctonus pseudotsugae hopkins (Coleoptera: Scolytidae), to pheromones and host odors," Journal of Chemical Ecology, vol. 10, no. 4, pp. 583-600, 1984.

[36] J. C. Dickens, T. L. Payne, L. C. Ryker, and J. A. Rudinsky, "Multiple acceptors for pheromonal enantiomers on single olfactory cells in the Douglas-fir beetle, Dendroctonus pseudotsugae Hopk. (Coleoptera: Scolytidae)," Journal of Chemical Ecology, vol. 11, no. 10, pp. 1359-1370, 1985.

[37] T. L. Payne, J. V. Richerson, J. C. Dickens et al., "Southern pine beetle: olfactory receptor and behavior discrimination of enantiomers of the attractant pheromone frontalin," Journal of Chemical Ecology, vol. 8, no. 5, pp. 873-881, 1982.

[38] J. C. Dickens and T. L. Payne, "Bark beetle olfaction: pheromone receptor system in Dendroctonus frontalis," Journal of Insect Physiology, vol. 23, no. 4, pp. 481-489, 1977.

[39] B. Å. Tømmerås and H. Mustaparta, "Single cell responses to pheromones, host and non-host volatiles in the ambrosia beetle Trypodendron lineatum," Entomologia Experimentalis et Applicata, vol. 52, no. 2, pp. 141-148, 1989.

[40] A. Guerrero, J. Feixas, J. Pajares, L. J. Wadhams, J. A. Pickett, and C. M. Woodcock, "Semiochemically induced inhibition of behaviour of Tomicus destruens (Woll.) (Coleoptera: Scolytidae)," Naturwissenschaften, vol. 84, no. 4, pp. 155-157, 1997.

[41] E. Hallberg, "Sensory organs in Ips typographus (Insecta: Coleoptera)-Fine structure of antennal sensilla," Protoplasma, vol. 111, no. 3, pp. 206-214, 1982.

[42] T. C. Baker, S. A. Ochieng, A. A. Cossé et al., "A comparison of responses from olfactory receptor neurons of Heliothis subflexa and Heliothis virescens to components of their sex pheromone," Journal of Comparative Physiology A, vol. 190, no. 2, pp. 155-165, 2004.

[43] H. Ljungberg, P. Anderson, and B. S. Hansson, "Physiology and morphology of pheromone-specific sensilla on the antennae of male and female Spodoptera littoralis (Lepidoptera: Noctuidae)," Journal of Insect Physiology, vol. 39, no. 3, pp. 253-260, 1993.

[44] G. Birgersson, F. Schlyter, J. Löfqvist, and G. Bergström, "Quantitative variation of pheromone components in the spruce bark beetle Ips typographus from different attack phases," Journal of Chemical Ecology, vol. 10, no. 7, pp. 10291055, 1984.

[45] M. N. Andersson and F. Schlyter, "What reaches the antenna? How to calibrate odor flux and ligand-receptor affinities," Chemical Senses. In press.

[46] I. M. Wilson, J. H. Borden, R. Gries, and G. Gries, "Green leaf volatiles as antiaggregants for the mountain pine beetle, Dendroctonus ponderosae Hopkins (Coleoptera: Scolytidae)," Journal of Chemical Ecology, vol. 22, no. 10, pp. 1861-1875, 1996.

[47] Q.-H. Zhang, N. Erbilgin, and S. J. Seybold, "GC-EAD responses to semiochemicals by eight beetles in the subcortical community associated with Monterey pine trees in coastal California: similarities and disparities across three trophic levels," Chemoecology, vol. 18, no. 4, pp. 243-254, 2008.

[48] D. P. W. Huber, R. Gries, J. H. Borden, and H. D. Pierce, "A survey of antennal responses by five species of coniferophagous bark beetles (Coleoptera: Scolytidae) to bark volatiles of six species of angiosperm trees," Chemoecology, vol. 10, no. 3, pp. 103-113, 2000.

[49] J. A. Byers, "Avoidance of competition by spruce bark beetles, Ips typographus and Pityogenes chalcographus," Experientia, vol. 49 , no. 3, pp. 272-275, 1993.

[50] B. S. Hansson, M. C. Larsson, and W. S. Leal, "Green leaf volatile-detecting olfactory receptor neurones display very high sensitivity and specificity in a scarab beetle," Physiological Entomology, vol. 24, no. 2, pp. 121-126, 1999.

[51] M. C. Larsson, W. S. Leal, and B. S. Hansson, "Olfactory receptor neurons detecting plant odours and male volatiles in Anomala cuprea beetles (Coleoptera: Scarabaeidae)," Journal of Insect Physiology, vol. 47, no. 9, pp. 1065-1076, 2001.

[52] H. Y. Fadamiro, A. A. Cossé, and T. C. Baker, "Fine-scale resolution of closely spaced pheromone and antagonist filaments by flying male Helicoverpa zea," Journal of Comparative Physiology, A, vol. 185, no. 2, pp. 131-141, 1999.

[53] T. J. A. Bruce, L. J. Wadhams, and C. M. Woodcock, "Insect host location: a volatile situation," Trends in Plant Science, vol. 10, no. 6, pp. 269-274, 2005.

[54] A. Vermeulen and J. P. Rospars, "Why are insect olfactory receptor neurons grouped into sensilla? The teachings of a model investigating the effects of the electrical interaction between neurons on the transepithelial potential and the neuronal transmembrane potential," European Biophysics Journal, vol. 33, no. 7, pp. 633-643, 2004.

[55] A. F. Silbering, R. Okada, K. Ito, and C. G. Galizia, "Olfactory information processing in the Drosophila antennal lobe: anything goes?" Journal of Neuroscience, vol. 28, no. 49, pp. 13075-13087, 2008.

[56] M. M. Blight, J. A. Pickett, L. J. Wadhams, and C. M. Woodcock, "Antennal perception of oilseed rape, Brassica napus (Brassicaceae), volatiles by the cabbage seed weevil Ceutorhynchus assimilis (Coleoptera, Curculionidae)," Journal of Chemical Ecology, vol. 21, no. 11, pp. 1649-1664, 1995.

[57] E. A. Hallem, M. G. Ho, and J. R. Carlson, "The molecular basis of odor coding in the Drosophila antenna," Cell, vol. 117, no. 7, pp. 965-979, 2004.

[58] J. E. Cometto-Muñiz, W. S. Cain, and M. H. Abraham, "Quantification of chemical vapors in chemosensory research," Chemical Senses, vol. 28, no. 6, pp. 467-477, 2003.

[59] T. Tsukatani, T. Miwa, M. Furukawa, and R. M. Costanzo, "Detection thresholds for phenyl ethyl alcohol using serial dilutions in different solvents," Chemical Senses, vol. 28, no. 1, pp. 25-32, 2003. 
[60] R. S. Vetter, A. E. Sage, K. A. Justus, R. T. Cardé, and C. G. Galizia, "Temporal integrity of an airborne odor stimulus is greatly affected by physical aspects of the odor delivery system," Chemical Senses, vol. 31, no. 4, pp. 359-369, 2006.

[61] M. N. Andersson, Olfaction in the spruce bark beetle, Ips typographus: receptor, neuron and habitat, Ph.D. dissertation, Swedish University of Agricultural Sciences, Alnarp, Sweden, 2011.

[62] R. De Jong and J. H. Visser, "Integration of olfactory information in the Colorado potato beetle brain," Brain Research, vol. 447, no. 1, pp. 10-17, 1988.

[63] K. Hansen, "Discrimination and production of disparlure enantiomers by the gypsy moth and the nun moth," Physiological Entomology, vol. 9, pp. 9-18, 1984.

[64] G. P. Svensson and M. C. Larsson, "Enantiomeric specificity in a pheromone-kairomone system of two threatened saproxylic beetles, Osmoderma eremita and Elater ferrugineus," Journal of Chemical Ecology, vol. 34, no. 2, pp. 189-197, 2008.

[65] H. Wojtasek, B. S. Hansson, and W. S. Leal, "Attracted or repelled? A matter of two neurons, one pheromone binding protein, and a chiral center," Biochemical and Biophysical Research Communications, vol. 250, no. 2, pp. 217-222, 1998.

[66] W. M. Getz and R. P. Akers, "Honeybee olfactory sensilla behave as integrated processing units," Behavioral and Neural Biology, vol. 61, no. 2, pp. 191-195, 1994.

[67] H. Jactel and E. G. Brockerhoff, "Tree diversity reduces herbivory by forest insects," Ecology Letters, vol. 10, no. 9, pp. 835-848, 2007.

[68] H. Jactel, G. Birgersson, S. Andersson, and F. Schlyter, "Nonhost volatiles mediate associational resistance to the pine processionary moth," Oecologia, vol. 166, no. 3, pp. 703-711, 2011.

[69] M. N. Andersson, M. Binyameen, M. M. Sadek, and F. Schlyter, "Attraction modulated by spacing of pheromone components and anti-attractants in a bark beetle and a moth," Journal of Chemical Ecology, vol. 37, no. 8, pp. 899-911, 2011.

[70] N. E. Gillette, J. D. Stein, D. R. Owen et al., "Verbenonereleasing flakes protect individual Pinus contorta trees from attack by Dendroctonus ponderosae and Dendroctonus valens (Coleoptera: Curculionidae, Scolytinae)," Agricultural and Forest Entomology, vol. 8, no. 3, pp. 243-251, 2006.

[71] J. A. Byers, "Interactions of pheromone component odor plumes of western pine beetle," Journal of Chemical Ecology, vol. 13, no. 12, pp. 2143-2157, 1987.

[72] B. T. Sullivan and K. Mori, "Spatial displacement of release point can enhance activity of an attractant pheromone synergist of a bark beetle," Journal of Chemical Ecology, vol. 35, no. 10, pp. 1222-1233, 2009.

[73] G. H. L. Rothschild, "Problems in defining synergists and inhibitors of the Oriental Fruit Moth pheromone by field experimentation," Entomologia Experimentalis et Applicata, vol. 17, no. 2, pp. 294-302, 1974.

[74] P. Witzgall and E. Priesner, "Wind-tunnel study on attraction inhibitor in male Coleophora laricella Hbn. (Lepidoptera: Coleophoridae)," Journal of Chemical Ecology, vol. 17, no. 7, pp. 1355-1362, 1991.

[75] M. Coracini, M. Bengtsson, L. Cichon, and P. Witzgall, "Codling moth males do not discriminate between pheromone and a pheromone/antagonist blend during upwind flight," Naturwissenschaften, vol. 90, no. 9, pp. 419-423, 2003.

[76] T. A. Christensen and J. G. Hildebrand, "Coincident stimulation with pheromone components improves temporal pattern resolution in central olfactory neurons," Journal of Neurophysiology, vol. 77, no. 2, pp. 775-781, 1997.
[77] R. Jakuš, F. Schlyter, Q.-H. Zhang et al., "Overview of development of an anti-attractant based technology for spruce protection against Ips typographus: from past failures to future success," Journal of Pest Science, vol. 76, no. 4, pp. 89-99, 2003.

[78] C. Schiebe, M. Blaženec, R. Jakuš, C. R. Unelius, and F. Schlyter, "Semiochemical diversity diverts bark beetle attacks from Norway spruce edges," Journal of Applied Entomology, vol. 135, no. 10, pp. 726-737, 2011.

[79] M. N. Andersson, J. M. Bengtsson, E. Grosse-Wilde et al., "Olfactory receptors in Ips typographus. Transcriptome from antenna analysed and preliminary compared to Dendroctonus ponderosae and Tribolium castaneum (Coleoptera: Curculionidae \& Tenebrionidae)," in Genetics of Bark Beetles and Associated Microorganisms, F. Lakatos, B. Mészáros, and C. Stauffer, Eds., p. 15, Sopron, Hungary, 2011.

[80] N. Triballeau, E. van Name, G. Laslier et al., "Highpotency olfactory receptor agonists discovered by virtual highthroughput screening: molecular probes for receptor structure and olfactory function," Neuron, vol. 60, no. 5, pp. 767-774, 2008.

[81] J. N. C. van der Pers and A. K. Minks, "Pheromone monitoring in the field using single sensillum recording," Entomologia Experimentalis et Applicata, vol. 68, no. 3, pp. 237-245, 1993. 

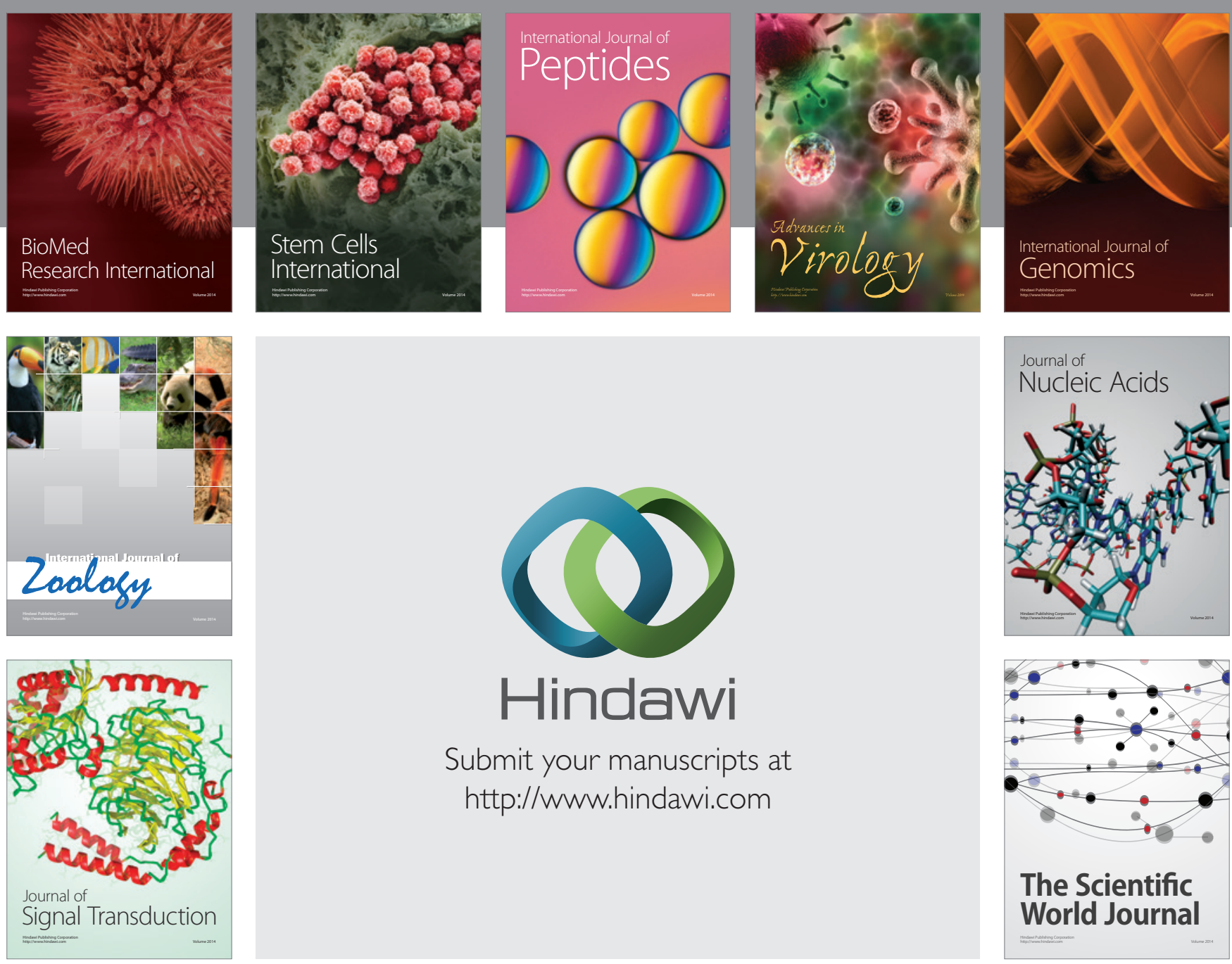

Submit your manuscripts at

http://www.hindawi.com
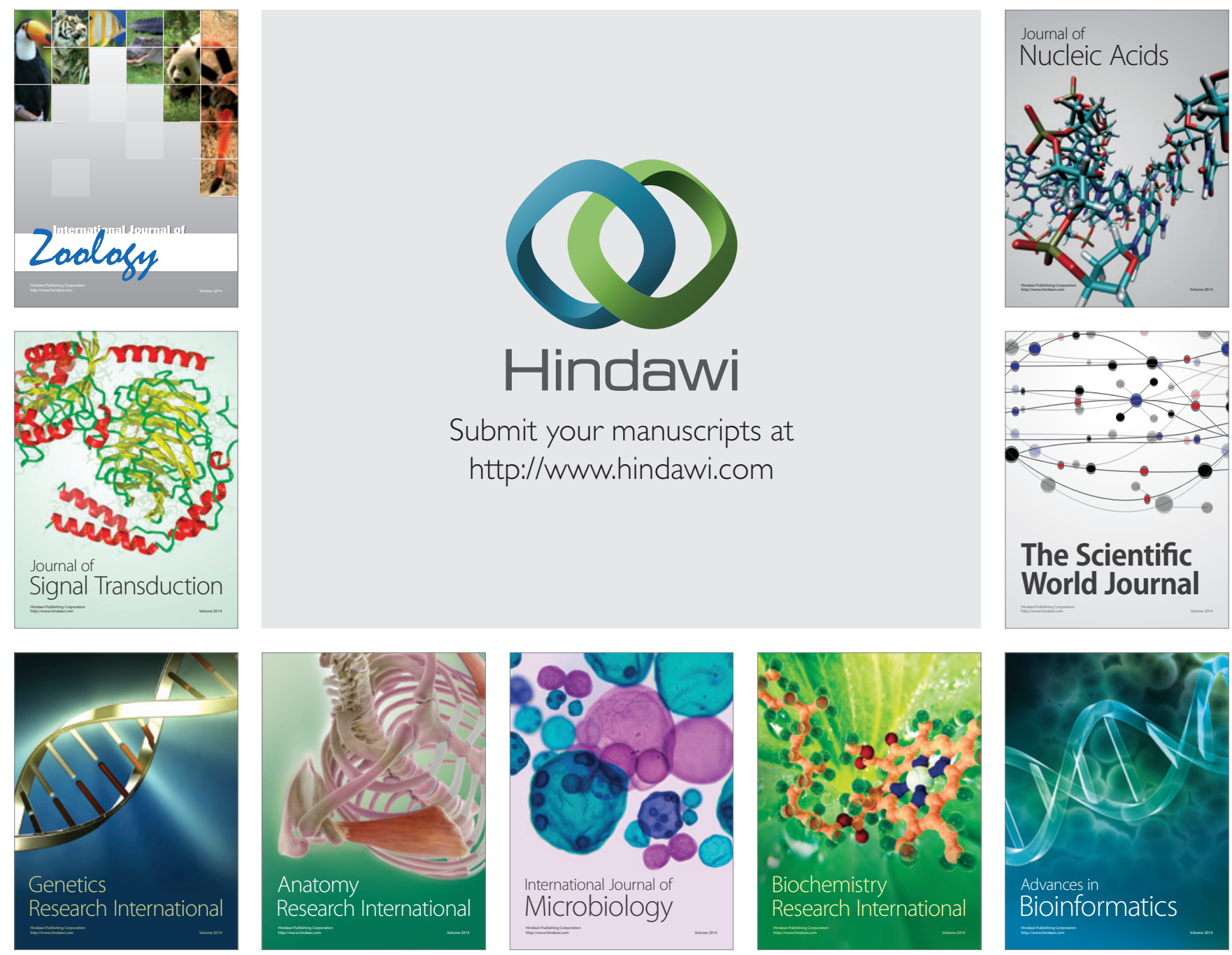

The Scientific World Journal
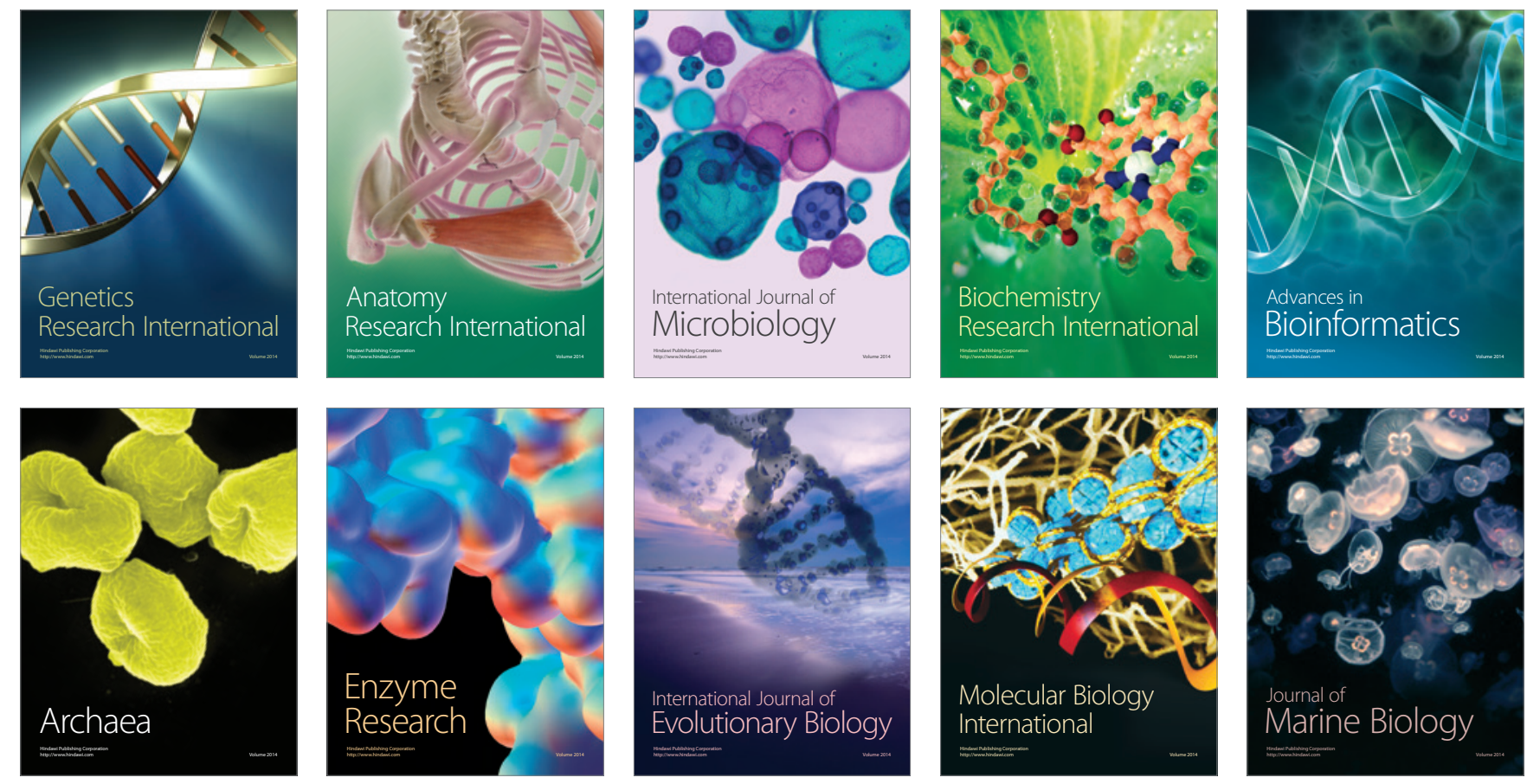